\title{
Investigating Land Surface Temperature Changes Using Landsat Data in Konya, Turkey
}

\author{
O. Orhan ${ }^{\mathrm{a} *}$, M. Yakar ${ }^{\mathrm{a}}$ \\ ${ }^{a}$ Dept. of Geomatic Engineering, Selcuk University, Konya, - osmanorhan44@gmail.com / yakar@ selcuk.edu.tr
}

Commission VIII, WG VIII/3

KEY WORDS: Land Surface Temperature, NDVI, Konya, Landsat, Drought

\begin{abstract}
:
The main purpose of this paper is to investigate multi-temporal land surface temperature (LST) and Normalized Difference Vegetation Index (NDVI) changes of Konya in Turkey using remotely sensed data. Konya is located in the semi-arid central Anatolian region of Turkey and hosts many important wetland sites including Salt Lake. Six images taken by Landsat-5 TM and Landsat 8- OLI satellites were used as the basic data source. These raw images were taken in 1984, 2011 and 2014 intended as longterm and short-term. Firstly, those raw images was corrected radiometric and geometrically within the scope of project. Three mosaic images were obtained by using the full-frame images of Landsat-5 TM / 8- OLI which had been already transformed comparison each other. Then, Land Surface Temperature (LST), Normalized Difference Vegetation Index (NDVI) maps have been produced to determine the dimension of the drought. The obtained results showed that surface temperature rates in the basin increased about $5^{\circ} \mathrm{C}$ between 1984 and 2014 as long periods, increased about $2-3^{\circ} \mathrm{C}$ between 2011 and 2014 as short periods. Meteorological data supports the increase in temperature.
\end{abstract}

\section{INTRODUCTION}

Earth's surface energy balance, thermal properties of surface and atmospheric conditions affect the land surface temperature dramatically (Srivastava et al. 2009). Global and local changes continues in the Earth's climate changes since the pre-industrial era continues. Some of the changes occurs due to natural phenomena and anthropogenic activities such as; greenhouse gas, land cover and land use change, uncontrolled use of groundwater, deforestation, rising water demands, urbanization, and irrigation activities. (Yan et al., 2002; Penny and Kealhofer, 2005; Kantarc1, 2006; Y1ldırım et al., 2011; Orhan et al., 2014).

Remote sensing is useful for understanding the spatiotemporal land cover change in relation to the basic physical properties in terms of the surface radiance and emissivity data. Since the 1970s, satellite-derived (such as Landsat-5/8) surface temperature data have been utilized for regional climate analyses on different scale (Tran et al. 2006; Carlson et al. 1977).Landsat having medium- resolution satellite is the only source of LST in worldwide since 1972. Therefore the Landsat$5 / 8$ satellite images were used in this study. Many researchers showed that the surface temperature of the work confirmed from Landsat-5/8(Xiao ve Weng, 2007; Amiri vd., 2009; Mallick vd., 2012; Guo vd., 2012; Li et al. 2016; Avdan and Jovanovska, 2016)

Land Surface Temperature (LST), used to determine the temperature distribution and the change in local or global scale, used in climate and climate change models in particular. LST, calculated from remote sensing data, is used in many areas of science; such as; hydrology, agriculture, climate change, urban planning, forestry, oceanography etc. Obtaining surface temperatures and using them in different analysis is important to determine the problem associated with the environment.(Orhan et al. 2014)
This study was conducted in Konya that located in the Central Anatolia, Turkey. Multitemporal thermal image series were acquired by Landsat -5 TM/8-OLI. The main goals of this study are;

-To investigate the change of Konya LST through multitemporal Landsat imagery collected from 1984 to 2011(short period) and from 2011 to 2014 (long period).

-To examine relationship between LST, NDVI and groundwater levels.

-To examined the accuracy of the LST with meteorological station

\section{METHODOLOGY}

\subsection{Study Region}

Konya is located in the semi-arid Central Anatolian Plateau at latitude $36.70^{\circ}-39.25^{\circ} \mathrm{N}$ and longitude $31.25^{\circ}-34.43^{\circ} \mathrm{E}$ and at an altitude of about $1,006 \mathrm{~m}$ in Turkey. The city is among the largest cities(41001 sq kilometres) and is one of the most populated city in the country. Neighboring provinces are Ankara to the north, Isparta, Afyonkarahisar, Eskişehir to the west, Mersin, Karaman and Antalya to the south and Niğde and Aksaray to the east. The Salt Lake, located within Konya boundaries, is the second biggest lake in Turkey. Depth of the lake is about 1,2 meters. Its surface area gets smaller in summer because of evaporation. The lake supplies a fair amount of Turkey's salt demand. Beysehir Lake is on the western part of Konya near Isparta-Konya border. Beysehir lake is the 3rd largest natural lake in Turkey and also the biggest fresh water lake in Turkey. It is also one of the most important national parks in Turkey. Konya, shown in Figure 1, has been known mainly for its agricultural activities and agriculture-based industries play a role its economy.

\footnotetext{
* Corresponding author
} 


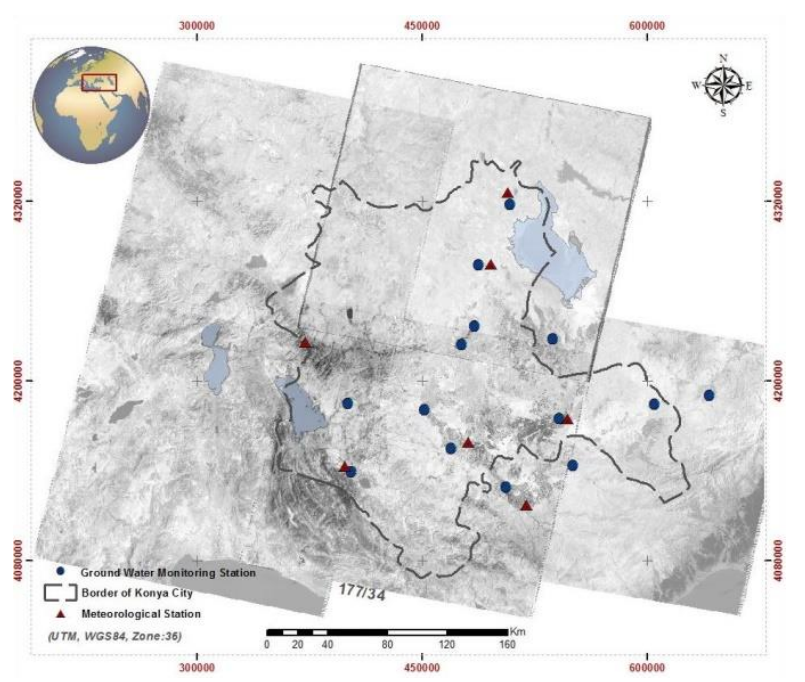

Figure 1. Study Area

\subsection{Data and Methods}

In this study, Landsat-5 and Landsat- 8 multispectral images which are listed in Table 1 were used as remote sensing data source. A cloud-free Landsat-5/8 images (path/row= 177/033177/34) ,acquired about August, 1984, 2011, and 2014, were used for generating LST maps. In the image processing step, satellite remote sensing data were geometrically transformed to real-world coordinates using UTM projection and WGS 84 datum. The IKONOS MS data having 4 meter spatial resolution and base maps (1:25 000) were used for the ground control, resulting in a root mean square (RMS) accuracy of less than a half pixel utilizing approximately 30 ground control points for each image. The nearest neighbour resampling method (Dymond and Shepherd, 2004; Yamaguchi and Naito, 2003) and a second order polynomial transformation method (Hellweger et al, 2004) were used to create the output images with $30 \mathrm{~m}$ ground resolution for Landsat- $5 / 8$ sensors data. The Landsat-5 Band 6 thermal data $(120 \mathrm{~m})$ and The Landsat- 8 Band 10 thermal data $(100 \mathrm{~m})$ were reprojected to using UTM projection and WGS 84 datum and converted to $30 \mathrm{~m}$. Thermal band was used to estimate brightness temperature and NIR and RED bands were used for calculating the NDVI. First, Landsat8,2014 , and then other historical images(Landsat-5) were radiometrically corrected to be able to compare with in situ infrared thermometer measurements, data of meteorological station and with each other (Orhan et al, 2014; Joshi and Bhatt, 2012).

\begin{tabular}{|c|c|}
\hline $\mathbf{1 7 7 / 3 3}$ & $\mathbf{1 7 7 / 3 4}$ \\
\hline 26.08 .1984 & 26.08 .1984 \\
\hline 21.08 .2011 & 21.08 .2011 \\
\hline $13.08 .2014^{*}$ & $13.08 .2014^{*}$ \\
\hline
\end{tabular}

Table 1. Landsat-5/8 frames covering the Konya (Turkey) used in the analysis.(* acquired Landsat-8)

To estimate the LST from the Landsat-5 thermal infrared band data, DN of sensors were converted to spectral radiance using the following equation (Eq. 1) (Chander and Groeneveld, 2009).
$L \lambda=\frac{L \max l-L \min \lambda}{Q \operatorname{calmax}-Q \operatorname{calmin}} \times(Q \operatorname{cal}-Q \operatorname{calmin})+L \min \lambda$

where the $\mathrm{L} \lambda$ is the cell value as radiance $(\mathrm{W} /(\mathrm{m} 2 \mathrm{sr} \mu \mathrm{m}))$, Q cal is the quantized calibrated digital number, $Q$ calmin is the minimum quantized calibrated pixel value, and $Q$ calmax is the maximum quantized calibrated pixel value; LMIN $\lambda$ is the spectral radiance scales to $\mathrm{Q}$ calmin , LMAX $\lambda$ is the spectral radiance scales to $\mathrm{Q}$ calmax.

To estimate the LST from the Landsat- 8 thermal infrared band data, DN of sensors were converted to spectral radiance using the following equation.

$L \lambda=\mathrm{ML} \times \mathrm{QCAL}+\mathrm{AL}-\mathrm{Qi}$

where $M L$ represents the band-specific multiplicative rescaling factor, $Q$ cal is the Band 10 image, $A L$ is the band-specific additive rescaling factor, and $\mathrm{Oi}$ is the correction for Band 10 (Barsi et al. 2014).

Spectral radiance was converted to brightness temperature by assuming the earth's surface is a black body (Eq. 3) (Orhan et al. 2014; Chander et al, 2009; Coll et al, 2010):

$T b=\frac{K 2}{\ln ((K 1 / L \lambda)+1)}-273.15$

where $\mathrm{Tb}$ is the brightness temperature, $\mathrm{L} \lambda$ is the cell value as radiance, $\mathrm{K} 1$ and $\mathrm{K} 2$ are the constants of Landsat-5 and Landsat- 8 calibration. For obtaining the results in Celsius, the brightness temperature is revised by adding the absolute zero $(-273.15 \circ \mathrm{C})$ (Orhan et al. 2014; Avdan and Jovanovska, 2016)

The brightness temperature was converted to land surface temperature using the following equation.

$T s=\frac{T b}{1+\left(\lambda \times \frac{T b}{\rho}\right) L N a \lambda}$

where $\lambda(11.45 \mu \mathrm{m}$ for Landsat 4,5 and $7 / 10.895 \mu \mathrm{m}$ for Landsat 8 band $10 / 12 \mu \mathrm{m}$ for Landsat 8 band 11) is the emitted radiance wavelength. $\rho(0.01438 \mathrm{mK})$ is generated from the equitation $\rho=\mathrm{h} * \mathrm{c} / \mathrm{b}$, in which $\mathrm{h}(6.626 * 10-34 \mathrm{Js})$ is the Planck's constant,c $(2.998 * 108 \mathrm{~m} / \mathrm{s})$ is the velocity of light, and $b$ $(1.38 * 10-23 \mathrm{~J} / \mathrm{K})$ is the Boltzmann constant, and $\varepsilon \lambda$ is the surface emissivity.

The land surface emissivity (LSE $(\varepsilon)$ ) must be known in order to estimate LST. The determination of the ground emissivity is calculated conditionally as suggested in (Sobrino et al. 2004).

$\varepsilon \lambda=\varepsilon v \lambda P v+\varepsilon s \lambda(1-P v)+C \lambda$

where $\varepsilon \mathrm{V}$ and $\varepsilon S$ are the vegetation and soil emissivities, respectively, $\mathrm{C} \lambda$ mean surface roughness $(\mathrm{C}=0$ for a flat surface) .In this study, LSE $(\varepsilon)$ extracted by using NDVI considering three different condition(soil,fully vegetated and mixture of bare soil and vegetation).

A method for calculating Proportion of Vegetation $(P V)$ (Wang et. al 2015). suggests using the NDVI values for vegetation and soil (NDVIV $=0.5$ and NDVI $s=0.2$ ) to apply in global conditions using the following equation. (Sobrino et al. 2004). 

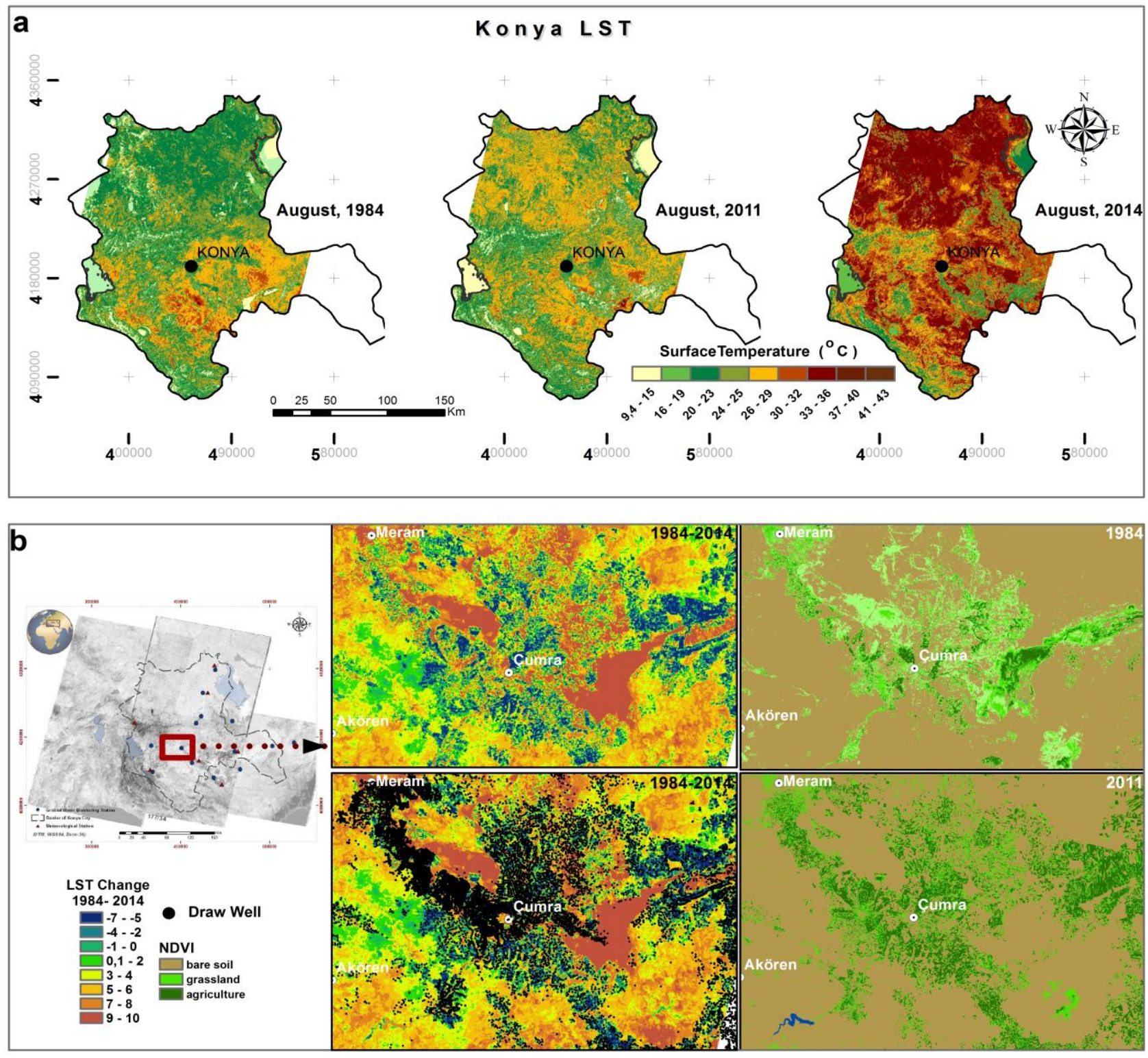

C

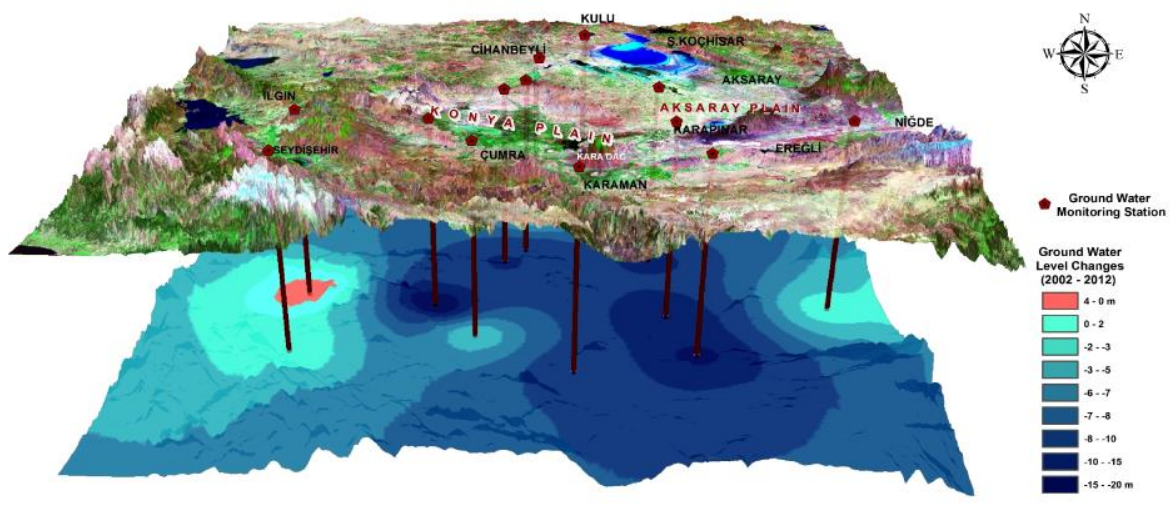

Figure 2. a-) Land Surface Temperature -1984/2011/2014 b-) Multitemporal NDVI maps and LST change for Konya c-) visualization of groundwater changes 
$P v=\left[\frac{N D V I-N D V I s}{N D V I v-N D V I s}\right]^{2}$

The NDVI is calculated as a ratio between measured reflectivity in the red and near infrared portions of the electromagnetic spectrum. These two spectral bands are chosen because they are most affected by the absorption of chlorophyll in leafy green vegetation and by the density of green vegetation on the surface. The NDVI transformation is computed using the following equation.

$N D V I=\frac{N I R-R E D}{N I R+R E D}$

\subsection{Calculating LSE for Landsat 5}

When NDVI values is less than 0.2 , it is considered that the surface is covered with soil and 0.97 is assigned as emissivity value. Values between 0.2 and 0.5 are considered mixtures of soil and vegetation cover and emissivity value of band 6 of Landsat-5 TM proposed by the authors in (Sobrino et al. 2004; Sobrino et al. 2008 ), therefore equations 8 is used to extract emissivity for mixtures of soil and vegetation cover. For NDVI values is greater than 0.5 , it is considered that the surface is covered with fully vegetated, and 0.99 is assigned as emissivity value.

$$
\varepsilon T M 6=0.986+0.004 P v
$$

\subsection{Calculating LSE for Landsat 8}

Using the ASTER spectral database (http://speclib.jpl.nasa.gov) the average emissivity of four representative terrestrial materials (Band10 water, building, soil, vegetation emissivities of 0.991, $0.962,0.966$ and 0.973, respectively) in Band 10 and Band 11 of Landsat 8 proposed by the authors in (Wang et. al 2015). Considering NDVI threshold values mentioned in above, the emissivity value of 0.966 is assigned for soil, the emissivity value of 0.973 is assigned for fully vegetated, and when NDVI values between 0.2 and 0.5 are considered mixtures of soil and vegetation cover and equations 5 is applied to retrieve the emissivity in this study.

\section{Validation of Land-Surface Temperature}

In this project, The correlation analysis was performed using hourly data of meteorological station for LST map of 2011 and 2014 derived Landsat 5 and Landsat- 8 satellite data. There are seven meteorological station in our study are. Result of regression analysis is 0.91 and $0.94 \mathrm{R}^{2}$ for 2011 derived from Landsat-5 and 2014 derived from Landsat- 8 respectively.

\section{CONCLUSION}

In this study,using Landsat satellite data, and Land Surface Temperature changes between the 1984-2014 and 2011-2014 years the relationship between it and the vegetation changes in groundwater levels were examined for Konya and its surroundings

Konya and around are observed temperature increase of $4-5{ }^{\circ} \mathrm{C}$. 2014 has been the year that most of the temperature. Generally, open areas, that is the northern and southern parts of the work area, are warmer. In particular, the reason for the the temperature rise in the southern zone of the region, the the transition point of the Mediterranean climate, the host province of Konya, and therefore, due to the effect of heat island is seen.

When analyzed NDVI, 2014 compared to 1984 in terms of density of plants include more agricultural areas and green fields in the region. the increase in the LST and agricultural areas caused an excessive amount of water needs It can be said value of surface temperature (increased of summer drought effect) is a continuous increase. As a source of water for agricultural activities is only used the underground water source, also be associated with the level seen in falling groundwater levels. it seems that the most important problem is the uncontrolled use of ground water resources in the region. As a result; When the value of 10 groundwater observation wells investigated in Konya province, it was observed that values decrease in general. It can be said to be affected The decrease in groundwater level by climatic effects and the use of water activities.

This study examined the relationship between thermal infrared band of the Landsat-5 for 2011 and Landsat-8 for 2014 and hourly data of meteorological station. The regression results showed that measured temperatures and LST were in good agreement with $R^{2}$ values over 0.90 .

\section{REFERENCES}

Amiri, R., Weng, Q., Alimohammadi, A., AlavipanahS. K., 2009. Spatial-temporal dynamics of land surface temperature in relation to fractional vegetation cover and land use/cover in the Tabriz urban area, Iran. Remote Sensing of Environment, 113, 2606-2617.

Chander, G., Groeneveld, D.P. 2009. Intra-annual NDVI validation of the Landsat $5 \mathrm{TM}$ radiometric calibration. International Journal of Remote Sensing, 30, 1621-1628.

Chander, G., Markham, B.L., Helder, D.L., 2009. Summary of current radiometric calibration coefficients for Landsat MSS, TM, ETM+, and EO-1 ALI sensors. Remote Sensing of Environment, 113, 893-903.

Coll, C., Galve, J.M., Sánchez, J.M., Caselles, V., 2010. Validation of landsat-7/ETM+ thermal-band calibration and atmospheric correction with ground-based measurements. IEEE Transactions on Geoscience and Remote Sensing, 48, 547-555.

Hellweger, F. L., Schlosser, P., Lall, U., Weissel, J. K., 2004. Use of satellite imagery for water quality studies in New York Harbor, Estuarine, Coastal and Shelf Science, vol. 61, no. 3, pp. 437-448.

Wang, F., Qin, Z., Song, C., Tu, L., Karnieli, A. Zhao, S.,2015. An improved mono-window algorithm for land surface temperature retrieval from landsat 8 thermal infrared sensor data, Remote Sensing, vol. 7, no. 4, pp. 4268-4289.

Guo, Z., Wang, S.D., Cheng, M.M., Shu, Y., 2012. Assess the effect of different degrees of urbanization on land surface temperature using remote sensing images. Procedia Environmental Sciences, 13, 935-942. 
H. Tran, D. Uchihama, S. Ochi, and Y. Yasuoka, “Assessment with satellite data of the urban heat island effects in Asian mega cities," International Journal of Applied Earth Observation and Geoinformation, vol. 8, no. 1, pp. 34-48, 2006.

J. A. Barsi, J. R. Schott, S. J. Hook, N. G. Raqueno, B. L. Markham, R. G. Radocinski., 2014 "Landsat-8 thermal infrared sensor (TIRS) vicarious radiometric calibration," Remote Sensing, vol. 6, no. 11, pp. 11607-11626.

J. P. Joshi, B. Bhatt., 2011 "Estimating temporal land surface temperature using remote sensing: a study of vadodara urban, Gujarat," International Journal of Geology, Earth and Environmental Sciences, vol. 2, pp. 123-130.

J. R. Dymond and J. D. Shepherd., 2004. The spatial distribution of indigenous forest and its composition in the Wellington region, New Zealand, from ETM+ satellite imagery," Remote Sensing of Environment, vol. 90, no. 1, pp. $116-125$.

Kantarci, M. D., 2006. Effects of climate change and aridity on Ergene River basin water productivity. In: International conference on climate change and Middle East: Past, present and future (pp. 246-258). Istanbul, Turkey, 20-23 November 2006.

Mallick, J., Singh, C. K., Shashtri, S., Rahman, A., Mukherjee, S., 2012. Land surface emissivity retrieval based on moisture index from LANDSAT TM satellite data over heterogeneous surfaces of Delhi city. International Journal of Applied Earth Observation and Geoinformation, 19, 348-358.

Orhan, O., Ekercin, S., Dadaser-Celik, F., 2014 Use of Landsat Land Surface Temperature and Vegetation Indices for Monitoring Drought in the Salt Lake Basin Area, Turkey, The Scientific World Journal, vol. 2014, Article ID 142939, 11 pages.doi:10.1155/2014/142939

Penny, D., Kealhofer, L., 2005. Microfossil evidence of landuse intensification in north Thailand. J Archaeol Sci. 32,69-82.

Sobrino, J.A., Jimenez-Munoz, J.C., Paolini, L. 2004. Land surface temperature retrieval from LANDSAT TM 5. Remote Sensing of Environment, 90, 434-440.

Sobrino, J.A., Jiménez-Muñoz, J.C., Sòria, G., Romaguera, M., Guanter, L., Moreno, J., Martínez, P., 2008. Land surface emissivity retrieval from different VNIR and TIR sensors. IEEE Transactions on Geoscience and Remote Sensing, 46, 316-327.

T. N. Carlson, J. A. Augustine, and F. E. Boland, 1977 Potential application of satellite temperature measurements in the analysis of land use over urban areas, Bulletin of the American Meteorological Society, vol. 58, pp. 1301-1303, 1977.

Avdan, U., Jovanovska, G., 2016 Algorithm for Automated Mapping of Land Surface Temperature Using LANDSAT 8 Satellite Data, Journal of Sensors, vol. 2016, Article ID 1480307, 8 pages,. 2016. doi:10.1155/2016/1480307.

Xiaoxiao Li, Wenwen Li, A. Middel, S.L. Harlan, A.J. Brazel, B.L. Turner II., 2016.Remote sensing of the surface urban heat island and land architecture in Phoenix, Arizona: Combined effects of land composition and configuration and cadastral- demographic-economic factors, Remote Sensing of Environment, Volume 174, 1 March 2016, Pages 233-243, ISSN 0034-4257, http://dx.doi.org/10.1016/j.rse.2015.12.022.

Y. Yamaguchi and C. Naito, "Spectrail indices for lithologic discrimination and mapping by using the ASTER SWIR bands," International Journal of Remote Sensing, vol. 24, no. 22, pp. 4311- 4323, 2003.

Yan, P., Shi, P., Gao, S., Chen, L., Zhang, X., Bai, L., 2002. 137Cs dating of lacustrine sediments and human impacts on Dalian Lake, Qinghai Province, China. Catena. 47,91-99.

Yıldırım, U,. Erdogan, S,. Uysal, M,. 2011. Changes in the Coastline and Water Level of the Aksehir and Eber Lakes Between 1975 and 2009. Water Resources Management. 25:941-962. doi:10.1155/2014/142939 